\title{
Laryngoscopic Examination During the COVID-19 Pandemic: Turkish Voice Speech and Swallowing Disorders Society and Turkish Professional Voice Society Recommendations
}

\author{
Quick Practice Guide \\ H. Bengü Çobanoğlu ${ }^{1}$ (D), Necati Enver² (1), Sevtap Akbulut ${ }^{3}$ (D), E. Özlem Atmış ${ }^{4}$ (D),

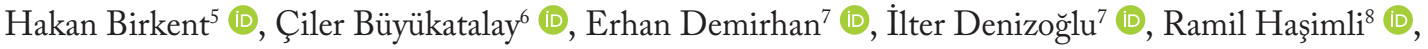 \\ Müge Özçelik Korkmaz ${ }^{9}$ (D), Selmin Karataylı Özgürsoy ${ }^{10}$ (), Kayhan Öztürk ${ }^{11}$ (D), Ceki Paltura' ${ }^{12}$ (1), \\ Seher Şirin ${ }^{13}$ (D), Emel Çadallı Tatar ${ }^{14}$ (D), Arzu Tüzüner ${ }^{15}$ (D), Kürşat Yelken ${ }^{16}$ (D), H. Hakan Coşkun ${ }^{17}$ (D), \\ Haldun Oğuz ${ }^{18}$ (D), Ferhan $\mathrm{Ö}^{19}$ (D) \\ ${ }^{1}$ Department of Otolaryngology, Head and Neck Surgery, Karadeniz Technical University School of Medicine, Trabzon, Turkey \\ ${ }^{2}$ Department of Otolaryngology, Head and Neck Surgery, Pendik Training and Research Hospital, Marmara University, İstanbul, Turkey \\ ${ }^{3}$ Department of Otolaryngology, Head and Neck Surgery, Yeditepe University School of Medicine, İstanbul, Turkey \\ ${ }^{4}$ Department of Otolaryngology, Head and Neck Surgery, Fulya Acıbadem Hospital, İstanbul, Turkey \\ ${ }^{5}$ Department of Otolaryngology, Head and Neck Surgery, İstanbul Cerrahi Hospital, İstanbul, Turkey \\ ${ }^{6}$ Department of Otorhinolaryngology, Head and Neck Surgery, İbni Sina Hospital, Ankara University School of Medicine, Ankara, Turkey \\ ${ }^{7}$ Private Practice, İzmir, Turkey \\ ${ }^{8}$ Department of Otorhinolaryngology, Head and Neck Surgery, Lor Hospital, Baku, Azerbaijan \\ ${ }^{9}$ Department of Otorhinolaryngology, Head and Neck Surgery, Sakarya Training and Research Hospital, Sakarya, Turkey \\ ${ }^{10}$ Department of Otorhinolaryngology, Head and Neck Surgery, Ufuk University School of Medicine, Ankara, Turkey \\ ${ }^{11}$ Department of Otorhinolaryngology, Head and Neck Surgery, Medicana Hospital, Konya, Turkey \\ ${ }^{12}$ Department of Otorhinolaryngology, Head and Neck Surgery, Gaziosmanpaşa Training and Research Hospital, İstanbul, Turkey \\ ${ }^{13}$ Department of Otolaryngology, Head and Neck Surgery, Kocaeli University School of Medicine, Kocaeli, Turkey \\ ${ }^{14}$ Department of Otorhinolaryngology, Head and Neck Surgery, Dışkapı Training and Research Hospital, Ankara, Turkey \\ ${ }^{15}$ Department of Otorhinolaryngology, Head and Neck Surgery, Başkent University School of Medicine, Ankara, Turkey \\ ${ }^{16}$ Department of Otorhinolaryngology, Head and Neck Surgery, Maltepe University School of Medicine, İstanbul, Turkey \\ ${ }^{17}$ Department of Otolaryngology, Head and Neck Surgery, Uludağ University School of Medicine, Bursa, Turkey \\ ${ }^{18}$ Department of Otorhinolaryngology, Head and Neck Surgery, Private Practice, Ankara, Turkey \\ ${ }^{19}$ Department of Otolaryngology, Head and Neck Surgery, Bakırköy Acıbadem Hospital, İstanbul, Turkey
}

\section{Abstract}

ORCID iDs of the authors: H.B.C. 0000-0003-3701-1697; N.E. 0000-0002-3161 8810; S.A. 0000-0003-3334-657X:E.O.A. 0000-0001 8810; S.A. 0000-0003-3334-657X;E.0.A. C..B. 0000-0002-0992-0079; E.D. 0000-0001-8871 0821; i.D. 0000-0002-9030-9479; R.H. 0000-00032549-4310; M. ̈.K. 0000-0003-4726-7987; S.K.0. 0000-0003-3272-492X;K.0.00000-0001-8141-0965; CP. 0000-0002-0971-3643.5 $5.0000-0002-2982-$ 9379. E. T. 0000-0003-3365-6308; AT, 0000-00019379, E.C.T. 0000-0003-3365-6308; A.T. 0000-00019000-0002-0881-1444; H.0.0000-0003-2106-4735; F.0̈. 0000-0002-5691-1431.

Cite this article as: Cobanoglu $H B$, Enver N, Akbulut S, Atmıs EÖ, Birkent H, Büyükatalay Ç, et al. Laryngoscopic Examination During the COVID-19 Pandemic: Turkish Voice Speech and Swallowing Disorders Society and Turkish Professional Voice Society Recommendations. Turk Arch Otorhinolaryngol 2020; 58(4): 274-8.

\section{Corresponding Author:}

H. Bengü Çobanoğlu, benguyc@gmail.com

Received Date: 25.06 .2020

Accepted Date: 15.09 .2020

Available Online Date: 23.10 .2020

Content of this journal is licensed under a Creative Commons Attribution 4.0 International License. Available online at www.turkarchotolaryngol.net

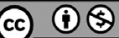

D0l: $10.5152 / \operatorname{ta0} 0.2020 .5719$

COVID-19 is highly transmissible and spreads rapidly in the population. This increases the occupational risk for health care workers. In otolaryngology clinic practice, patients with upper respiratory tract infection symptoms are common. Also, routine head and neck examinations such as oral cavity examination, nasal/nasopharyngeal examination, or video laryngostroboscopic evaluation are highly risky because of the aerosol formation. To emphasize this issue, two leading otolaryngology organizations in Turkey; 'Voice Speech and Swallowing Disorders Society',

\section{Introduction}

At the end of 2019, an infectious respiratory disease caused by severe acute respiratory coronavirus 2 syndrome (SARS-CoV2) has resulted in a worldwide health crisis known as Coronavirus disease 2019 (COVID-19). On March 11, 2020 COVID-19 was declared as a global pandemic by the World Health Organization (WHO). As of August 11, 2020, a total of 19,936,210 cases and 'Professional Voice Society' gathered a task force. This task force aimed to prepare a consensus report that would provide practical recommendations of the safety measurements during routine clinical care of laryngology patients. To fulfill this, universal aim, on the $2^{\text {nd }}$ and $9^{\text {th }}$ of May 2020, two web-based meetings were conducted by 20 expert physicians. This eighteen items list was prepared as an output.

Keywords: Laryngoscopy, endoscopic examination, COVID-19, pandemic, universal precautions of COVID-19 in 216 countries and regions have been confirmed, and more than 700 thousand deaths were reported by that time (1).

COVID-19 is highly transmissible and spreads rapidly in the population. This increases the occupational risk for health care workers. Especially at the beginning of the pandemic, many health care workers, including otolaryngologists, were mostly 
infected as a result of a lack of awareness and plans for managing infections (2). Higher rates of infection in otolaryngology have been reported in many countries (3). This higher rate of infection among otolaryngologists would be expected to be lower in the post surge era. Additionally, usage of the personal protective types of equipment will help otolaryngologists to protect themselves. In contrast, the number of patients would be expected to get higher every day with getting back to their normal clinical flow in that post-surge, pre-vaccination era.

In otolaryngology practice, patients with upper respiratory tract infection symptoms are common. Also, routine head and neck examinations such as oral cavity examination, nasal/nasopharyngeal examination, or video laryngostroboscopic evaluation are highly risky for the aerosol formation (4). Furthermore, most of the otolaryngologic examinations can be a trigger for coughing and sneezing, which are also known with aerosol generation (5).

Laryngology is one of the subspecialties of otolaryngology that focuses on voice, airway, and swallowing problems. Almost every patient with laryngological symptoms deserves laryngeal evaluation with either transoral rigid laryngoscopy or transnasal flexible laryngoscopy. Rigid transoral laryngoscopy with its high-resolution image quality is very beneficial for the examination of vocal fold mucosal lesions (6). Flexible laryngoscopy is also the gold standard examination of larynx and pharynx and is one of the most commonly performed otolaryngology procedures (7). Although in a recent study the transoral and transnasal laryngoscopy was not shown as aerosol-forming procedures, both examinations still carry the risk of a higher rate of aerosol production and laryngologists will have the burden of infection during this post-surge pre-vaccination era as well as the patients (8).

Recognizing the unprecedented challenges that we are facing or continuing the clinical care, otolaryngologists and patients have concerns about the uncertainty of measures that should be taken for safety. Until scientific advances allow for treatment or prevention for this infection disease, additional cautions should be taken by physicians and health organizations. To address that issue two of the leading otolaryngology organizations in Turkey;

\section{Main Points}

- At the end of 2019, an infectious respiratory disease caused by severe acute respiratory coronavirus 2 syndrome (SARS-CoV2) has resulted in a worldwide health crisis known as Coronavirus disease 2019 (COVID-19). On March 11, 2020 COVID-19 was declared as a global pandemic by the World Health Organization (WHO).

- During COVID-19 pandemic, modifications in laryngology practice are needed due to the new clinical conditions. To enlighten this situation, considering the dynamics of our health system, Turkish Speech and Swallowing Disorders Society and Professional Voice Society members organized online meetings to prepare the following suggestions by taking into consideration of current scientific papers about 'the new normal.'

- This 18 item list would be expected to serve as recommendations for the safety of patients and physicians.
'Voice Speech and Swallowing Disorders Society' and 'Professional Voice Society' gathered a task force. This task force aimed to prepare a consensus report that would provide practical recommendations of the safety measurements during routine clinical care of laryngology patients. To fulfill this aim, on the $2^{\text {nd }}$ and $9^{\text {th }}$ of May 2020, two web-based meetings were conducted by 20 expert physicians. And this eigtheen-item list was prepared as an output.

\section{Laryngoscopic Examination During the COVID-19 Pandemic}

During COVID-19 pandemic, modifications in laryngology practice are needed due to the new clinical conditions. To enlighten this situation, considering the dynamics of our health system, Turkish Speech and Swallowing Disorders Society and Professional Voice Society members organized online meetings to prepare the following suggestions by taking into the consideration of current scientific papers about 'the new normal':

1- All patients should maintain appropriate secure distance requirements in the waiting area. Consider removing and blocking off furniture in waiting areas to allow for secure distance $(9,10)$.

2- Maximize alcohol-based hand antiseptics vacancy and access if available. If these antiseptics are not available, encourage hand washing for staff and patients.

3- Laryngoscopic examinations should be planned carefully by taking the following precautions in cases that present hoarseness, shortness of breath, dysphagia, hemoptysis, and neck masses with unknown primary reasons (11).

4- If possible, Ear Nose Throat (ENT) examination and laryngoscopy should not be performed in the same room. The laryngoscopic examination room (LER) should have laminar airflow. If it is not available, LER should be a ventilated room. Even this is not possible, windows and doors of the room should be left open (room should be in accordance with WHO norms). If there is not such a facility, the room should be regularly and frequently ventilated (12).

5- Consider questioning the patient for possible COVID-19 symptoms before video laryngostroboscopic examinations. If possible, fever should be measured before taking the patient to the LER.

Patients who answer 'yes' to one or more of the following questions should be guided to the COVID-19 outpatient clinic(13):

Have you had close contact with COVID-19 (+) patients? Have you had one of these (fever or chills, cough, sore throat, shortness of breath or difficulty breathing, fatigue, muscle or body aches, headache, the recent loss of taste or smell, sore throat, congested or runny nose, nausea or vomiting, diarrhea in the past 14 days)?

6- It is mandatory using personal protective equipment (PPE) such as N95 facemasks, eyewear/face shields, cap, and gown in laryngoscopic examinations due to the higher risk of aerosol transmission (14). A health professional should al- 
ways keep in mind that the most important and crucial step of the examination is using the right personal protective equipment.

7- Even in the laryngoscopic examination of patients who have been diagnosed as COVID-19 (-) regarding PCR, using N95 masks are suggested for health professionals. Hand disinfection should be provided for the patient as well as for his/her companion. Gloves and the mask should be used properly (15). Consider using double gloves, take off the top one after laryngoscopic examination properly.

8- Laryngoscopic examination can be performed either transoral with a rigid laryngoscope or transnasal with a flexible laryngoscope. Since the transoral route is thought to have more chance to produce aerosols and droplets, flexible laryngoscopy should be preferred in most of the cases (15, 16).

9- Although in voice disorders, stroboscopic evaluation is an important part of the examination, it can prolong the examination time. Not initiating stroboscopy during laryngoscopy should be exercised in appropriate cases to shorten the amount of time spent for active laryngeal examination.

10- Keeping in mind that viral particles can easily suspend in the air, consider using a topical decongestant and anesthetic patty only in necessary cases $(5,8)$. Aerosol sprays are not recommended. Besides, using sterile lubricant gel is suitable

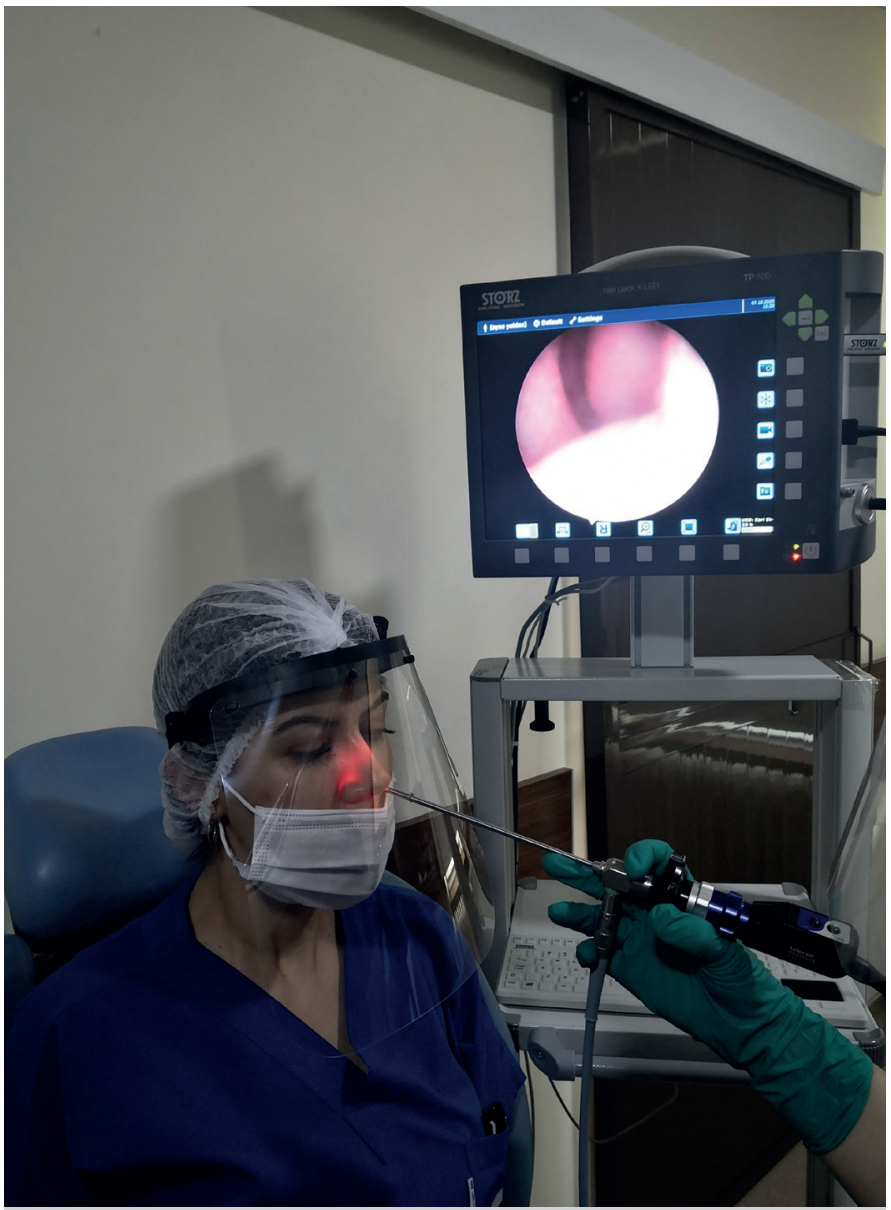

Figure 1. Nasal endoscopic examination through a punctured visor (with the permission of Department of Otorhinolaryngology, Uludağ University School of Medicine) for flexible laryngoscopy. It shouldn't be forgotten that also the use of suction during laryngoscopy has the potential to form aerosol.

11- Minimize the laryngoscopic examination time in LER for the patient preferably $<15$ minutes not just for patients' health, but also for the other health care workers in the room. Also consider taking a history before the visit via phone, web portal, or telehealth to minimize the time which the patient spends in the clinic (3).

12- Consider recording all laryngoscopic examinations to avoid repeat (unless necessary) the examination of the patient (17).

13- The laryngologist who will perform the examination should practice secure distance rules during the examination, must wash hands properly (with soap and at least 20 seconds under running water), apply standard disinfection methods before and after the examination (18). Consider taking the patient to the LER alone or to allow only one accompanying person in case of necessity.

14- During transoral laryngoscopic examination, consider shifting the patient's mask upward, and consider shifting the mask downward if a transnasal examination is needed. Using a disposable otoscope tip shaped for laryngoscopy can be another alternative. Also, a modified visor can be an option for these examinations (Figure 1,2).

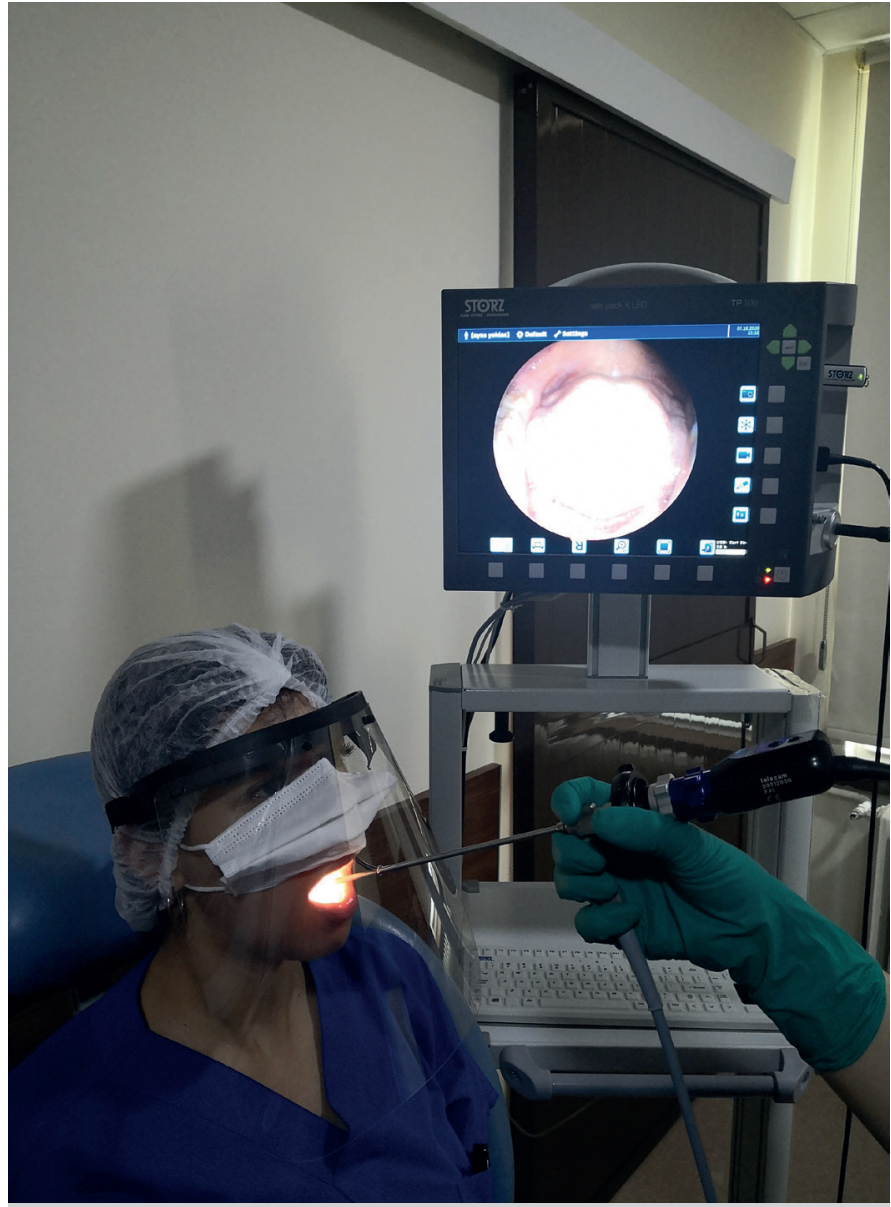

Figure 2. Transoral endoscopic examination through a punctured visor (with the permission of Department of Otorhinolaryngology, Uludağ University School of Medicine) 
15- The guideline of the Turkish Disinfection Antisepsis Sterilization Society considers 'laryngoscope' as a semi-critical device that requires high-level disinfection (18). According to this guideline, high-level disinfection ranges from gas sterilization with ethylene oxide to chemical sterilization with isopropyl alcohol, glutaraldehyde, chlorine dioxide, or orthophitaldehyde. Except for 70\% isopropyl alcohol, all of these methods can be used to prevent viral transmission. Consider disinfecting not just the tip of the laryngoscope but completely (19). After the procedure, the laryngoscope should be removed from the room in a closed container to prevent contamination and fomite transmission. The health-care worker responsible for the disinfection of the tools should wash hands before and after the procedure.

16- The LER should be properly disinfected after the examination. All the surfaces that the patient or the accompany touched should be cleaned with disinfectants. It is recommended to use 2-3\% hydrogen peroxide, $2-5 \mathrm{~g} / \mathrm{L}$ chlorine disinfectant solutions, or $75 \%$ alcohol. According to the recommendations of the Center for Disease Control and Prevention (CDC), the time required for disinfection with isopropyl alcohol is 5 minutes, while it can take 30 minutes for disinfecting with hydrogen peroxide and other materials (20).

17- As an alternative method, consider the disinfection of LER with Ultraviolet-C (UV-C) light (UV-C lamps). However, unlike chloroquine and its variants, UV-C does not offer any residual disinfection capacity leaving supplies vulnerable to microbial contamination (21). Our knowledge of UV sterilization comes from previous MERS and SARS experience. Within the confines of distribution of ultraviolet light (10-400 nm), Ultraviolet-C (100-280 nm) has the highest disinfectant capacity (with a peak-effect wavelength of $265 \mathrm{~nm}$ ) (22). Using a 15-watt UV-C lamp for $20 \mathrm{~min}$ utes will be sufficient in disinfection for rooms that are up to 30 sq. meters (23). Due to the side effects of UV-C on skin and cornea, caution signs must be placed in the room. Make sure that there is no one inside the room during disinfection with UV-C (24).

18- Considering the cleaning and disinfection time of the LER, there should be enough time between two patients that undergo laryngoscopic examination $(7,15,17)$.

\section{Conclusion}

This list is far away to be complete for the prevention of the spread of the infection. With the advancements in the knowledge about disease spread and efficient techniques that can be used for prevention, changes should be considered in the future. In the meantime, this consensus report would be expected to serve as recommendations for the safety of patients and physicians.

Peer-review: Externally peer-reviewed.

Author Contributions: Concept - H.B.Ç., N.E., S.A., E.Ö.A., H.B., Ç.B., E.D., İ.D., R.H., M.Ö.K., S.K.Ö., K.Ö., C.P., S.Ş., E.Ç.T., A.T., K.Y., H.H.C., H.O., F.Ö.; Design - H.B.Ç., N.E., S.A., E.Ö.A., H.B., Ç.B., E.D., İ.D., R.H., M.Ö.K., S.K.Ö., K.Ö., C.P., S.Ş., E.Ç.T., A.T.,
K.Y., H.H.C., H.O., F.Ö.; Supervision - H.B.Ç., N.E., S.A., E.Ö.A., H.B., Ç.B., E.D., I.D., R.H., M.Ö.K., S.K.Ö., K.Ö., C.P., S.Ş., E.Ç.T., A.T., K.Y., H.H.C., H.O., F.Ö.; Materials - H.B.Ç., N.E., Ç.B., E.D., İ.D., R.H.; Data Collection and/or Processing - N.E., M.Ö.K., S.K.Ö., K.Ö., C.P.; Analysis and/or Interpretation - H.B.Ç., S.Ş., E.Ç.T., A.T.; Literature Search - K.Y., N.E., H.B.Ç.; Writing - H.B.Ç., N.E., S.A.; Critical Reviews - F.Ö., H.H.C., H.O.

Conflict of Interest: The authors have no conflicts of interest to declare.

Financial Disclosure: The authors declared that this study has received no financial support.

\section{References}

1. World Health Organization (WHO). Coronavirus Disease 2019 (COVID- 19): Situation Report-146. Geneva, Switzerland. https://www.who.int/docs/default-source

2. Vukkadala N, Qian ZJ, Holsinger FC, Patel ZM, Rosenthal E. COVID-19, and the otolaryngologist: preliminary evidence-based review. Laryngoscope. 2020 Mar 26. doi: 10.1002/lary.28672. [Epub ahead of print].

3. Chan JYK, Wong EWY, Lam W. Practical aspects of otolaryngologic clinical services during the 2019 novel coronavirus epidemic: an experience in Hong Kong. JAMA Otolaryngol Head Neck Surg. 2020; 146: 519-20.

4. Workman AD, Jafari A, Welling DB, Varvares MA, Gray ST, Holbrook EH, et al. Airborne aerosol generation during endonasal procedures in the era of COVID-19: risks and recommendations. Otolaryngol Head Neck Surg 2020; 163: 465-70.

5. Tran K, Cimon K, Severn M, Pessoa-Silva CL, Conly J. Aerosol generating procedures and risk of transmission of acute respiratory infections to healthcare workers: a systematic review. PloS one. 2012; 7: e35797.

6. Chummun S, Winter SC, Draper MR. Prospective, randomized, single- blinded study comparing the use of a flexible nasendoscope and a rigid laryngoscope in outpatient laryngeal and pharyngeal examinations.J Otolaryngol Head Neck Surg 2009;38:15.

7. Rameau A, Young VN, Amin MR, Sulica L. Flexible laryngoscopy and COVID-19. Otolaryngol Head Neck Surg 2020; 162: 813-5.

8. Rameau A, Lee M, Enver N, Sulica L. Is office laryngoscopy an aerosol-generating procedure? Laryngoscope. 2020. doi: 10.1002/ lary.28973. [Epub ahead of print].

9. Saadi RA, Bann DV, Patel VA, Goldenberg D, May J, Isildak H. A commentary on safety precautions for otologic surgery during the Covid-19 pandemic. Otolaryngol Head Neck Surg. 2020; 162: 797-9.

10. https://covid19bilgi.saglik.gov.tr/depo/rehberler/COVID-19_ Rehberi.pdf?type=file

11. https://www.cdc.gov/coronavirus/2019-ncov/symptoms-testing/ symptoms.html

12. Özel F, Hançer Z. Hastanelerde iklimlendirme sistemleri. Tesisat Mühendisleri Dergisi 2005; 89: 27-42.

13. https://covid19bilgi.saglik.gov.tr/depo/formlar/COVID19-VAKA-SORGULAMA-KILAVUZU-A4_1.pdf

14. Wahidi MM, Lamb C, Murgu S, Musani A, Shojaee S, Sachdeva A, et al. American Association for Bronchology and Interventional Pulmonology (AABIP) statement on the use of bronchoscopy 
and respiratory specimen collection in patients with suspected or confirmed COVID-19 infection. J Bronchology Interv Pulmonol 2020; 27: e52-4.

15. Kowalski LP, Sanabria A, Ridge JA, Ng WT, de Bree R, Rinaldo A, et al. COVID-19 pandemic: effects and evidence-based recommendations for otolaryngology and head and neck surgery practice. Head Neck 2020; 42: 1259-67.

16. Ost DE. Bronchoscopy in the age of COVID-19. J Bronchology Interv Pulmonol 2020; 27: 160-2.

17. Syamal M. Literature guided recommendations for otolaryngologists during the COVID-19 pandemic: a contemporary review. Laryngoscope Investig Otolaryngol 2020; 5: 432-7.

18. https:/www.das.org.tr/kitaplar/DASRehber2019V10.pdf

19. https://prohousekeepers.com/wp-content/uploads/2020/04/ COVID-19_Cleaning_Playbook_Workplace.pdf

20. Saadi RA, Bann DV, Patel VA, Goldenberg D, May J, Isildak H. A commentary on safety precautions for otologic surgery during the
COVID-19 Pandemic. Otolaryngol Head Neck Surg 2020; 162: 797-9.

21. Torres AE, Lyons AB, Narla S, Kohli I, Parks-Miller A, Ozog $\mathrm{D}$, et al. Ultraviolet-C and other methods of decontamination of filtering facepiece N-95 respirators during the COVID-19 pandemic. Photochem Photobiol Sci. 2020 May 15. doi: 10.1039/ d0pp00131g. [Epub ahead of print].

22. Petersson LP, Albrecht UV, Sedlacek L, Gemein S, Gebel J, Vonberg RP. Portable UV light as an alternative for decontamination. Am J Infect Control 2014; 42: 1334-6.

23. Dexter F, Parra MC, Brown JR, Loftus RW. Perioperative Covid-19 defense: an evidence-based approach for optimization of infection control and operating room management. Anesth Analg 2020; 131: 37-42.

24. Gray NF. Microbiology of Waterborne diseases. $2^{\text {nd }}$ ed. London: Academic Press, Microbiological Aspects and Risks 2014, pp: 617-30. 